\title{
Commentary: Say yes to NO!
}

\author{
Alberto Benazzo, MD, and \\ Konrad Hoetzenecker, MD, PhD
}

Ex vivo lung perfusion (EVLP) has become an indispensable safety net in lung transplantation, as it allows to evaluate marginal donor lungs for an extended period of time before accepting them for transplantation. However, the potential of EVLP goes far beyond a "simple" organevaluation tool. It also represents a platform to recondition damaged donor lungs by targeted therapeutic interventions. The use of high-dose antibiotics during EVLP has previously been shown to significantly reduce the microbial $\operatorname{load}^{1}$; however, its clinical applicability is limited by the varying microbial spectrum of donor lungs and by the difficulty to target multidrug-resistant bacteria.

In the article "Pulmonary Safety of Continuous 12-hour Delivery of Antimicrobial Doses of Inhaled Nitric Oxide During Ex Vivo Lung Perfusion," Michaelsen and colleagues $^{2}$ tested the therapeutic potential of high-dose inhaled nitric oxide (iNO) during EVLP. In a first set of in vitro experiments, the antibacterial activity of highdose iNO was determined; subsequently, its therapeutic safety was investigated in a pig model of EVLP. The authors showed that iNO could efficiently reduce bacterial growth, both in solid and liquid culture assays, and a continuous delivery of iNO over a 12-hour EVLP run did not induce pulmonary inflammation or impair graft function.

Today, low-dose iNO $(<20 \mathrm{ppm})$ is routinely used in a variety of disorders, including acute respiratory distress syndrome ${ }^{3}$ decompensated pulmonary hypertension, ${ }^{4}$ and pulmonary hypertension of the newborn..$^{5}$ By activating

\footnotetext{
From the Department of Thoracic Surgery, Medical University of Vienna, Vienna, Austria.

Disclosures: The authors reported no conflicts of interest.

The Journal policy requires editors and reviewers to disclose conflicts of interest and to decline handling or reviewing manuscripts for which they may have a conflict of interest. The editors and reviewers of this article have no conflicts of interest.

Received for publication Dec 9, 2020; revisions received Dec 9, 2020; accepted for publication Dec 10, 2020; available ahead of print Jan 12, 2021.

Address for reprints: Konrad Hoetzenecker, MD, PhD, Department of Thoracic Surgery, Medical University of Vienna, Waehringer Guertel 18-20, 1090 Vienna, Austria (E-mail: konrad.hoetzenecker@meduniwien.ac.at).

J Thorac Cardiovasc Surg 2022;163:850-1

$0022-5223 / \$ 36.00$

Copyright (c) 2020 by The American Association for Thoracic Surgery

https://doi.org/10.1016/j.jtcvs.2020.12.061
}

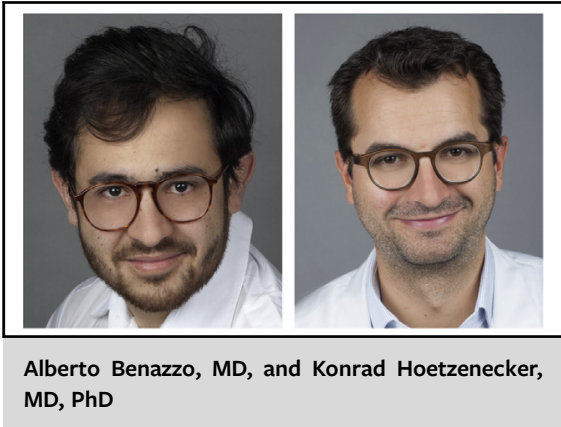

CENTRAL MESSAGE

Adding high-dose inhaled nitric oxide to ex vivo lung perfusion is a promising new approach to reduce the microbial load in donor lungs.

guanylyl cyclase in the pulmonary vascularity, iNO mediates vasodilation, reduces pulmonary vascular resistance, and thereby improves a ventilation-perfusion mismatch. Moreover, it has been shown that iNO exerts antiinflammatory and antiapoptotic effects. ${ }^{6,7}$ In the current study of the Toronto EVLP research group, iNO-treated lungs showed a trend toward an improved dynamic and static compliance as well as a reduction in pulmonary vascular resistance. Although this study primarily aimed to evaluate antimicrobial effects of iNO, these measurements point toward an additive beneficial effect of highdose iNO during EVLP.

Once more, the current work highlights the versatility of the Toronto EVLP platform and the great therapeutic potential that comes with it. Several examples can be found in the literature, ie, administration of fibrinolytic agents to dissolve pulmonary thromboemboli, ${ }^{8}$ the treatment of donor lungs with rituximab to deplete Epstein-Barr virus-bearing B cells, ${ }^{9}$ and the application of light therapy to inactivate circulating virus particles. ${ }^{10}$ The combination of high-dose iNO and EVLP constitutes a significant step toward a universal organ repair machine that can provide a variety of treatments tailored to the needs of each allograft.

In conclusion, high-dose iNO represents another part in the fascinating puzzle of ex vivo organ manipulation. In near future, a large proportion of reversible donor lung pathologies will be correctable by EVLP. Not all proposed therapeutic adjuncts of EVLP will find their way into the 
clinical practice, but the simplicity and the therapeutic potential of nitric oxide suggest a "yes" for NO.

\section{References}

1. Andreasson A, Karamanou DM, Perry JD, Perry A, Özalp F, Butt T, et al. The effect of ex vivo lung perfusion on microbial load in human donor lungs. J Heart Lung Transplant. 2014;33:910-6.

2. Michaelsen VS, Ribeiro RVP, Ali A, Wang A, Gazzalle A, Keshavjee S, et al, Safety of continuous 12-hour delivery of antimicrobial doses of inhaled nitric oxide during ex vivo lung perfusion. J Thorac Cardiovasc Surg. 2022; 163:841-9.e1.

3. Rossaint R, Falke KJ, Lopez F, Slama K, Pison U, Zapol WM. Inhaled nitric oxide for the adult respiratory distress syndrome. N Engl J Med. 1993;328:399-405.

4. Cheng JW, Tonelli AR, Pettersson G, Krasuski RA. Pharmacologic management of perioperative pulmonary hypertension. J Cardiovasc Pharmacol. 2014;63: 375-84.
}

5. Konduri GG, Kim UO. Advances in the diagnosis and management of persistent pulmonary hypertension of the newborn. Pediatr Clin North Am. 2009;56: 579-600, Table of Contents.

6. Gomez CB, del Valle HF, Bertolotti A, Negroni JA, Cuniberti L, Martinez V, et al. Effects of short-term inhaled nitric oxide on interleukin- 8 release after singlelung transplantation in pigs. J Heart Lung Transplant. 2005;24:714-22.

7. Yamashita H, Akamine S, Sumida Y, Inoue M, Sawada T, Nagayasu T, et al. Inhaled nitric oxide attenuates apoptosis in ischemia-reperfusion injury of the rabbit lung. Ann Thorac Surg. 2004;78:292-7.

8. Inci I, Yamada Y, Hillinger S, Jungraithmayr W, Trinkwitz M, Weder W. Successful lung transplantation after donor lung reconditioning with urokinase in ex vivo lung perfusion system. Ann Thorac Surg. 2014;98:1837-8.

9. Ku TJY, Ribeiro RVP, Ferreira VH, Galasso M, Keshavjee S, Kumar D, et al. Exvivo delivery of monoclonal antibody (Rituximab) to treat human donor lungs prior to transplantation. EBioMedicine. 2020;60:102994.

10. Galasso M, Feld JJ, Watanabe Y, Pipkin M, Summers C, Ali A, et al. Inactivating hepatitis $\mathrm{C}$ virus in donor lungs using light therapies during normothermic ex vivo lung perfusion. Nat Commun. 2019;10:481.

\section{Commentary: To use or not to use...Is NO the answer?}

\author{
Kenneth R. McCurry, MD, a,b,c \\ Toshihiro Okamoto, MD, $\mathrm{PhD},{ }^{\mathrm{a}, \mathrm{b}, \mathrm{c}}$ and \\ Kamal S. Ayyat, MD, $\mathrm{PhD}^{\mathrm{a}, \mathrm{b}}$
}

Normothermic ex vivo lung perfusion (EVLP) holds great promise as a platform to recondition donor lungs of unacceptable quality to make them suitable for transplantation. Experimental studies using EVLP as a platform for therapeutic interventions have included strategies to treat aspiration and hepatitis $\mathrm{C}$, among others. ${ }^{1,2}$ If successful and adopted broadly, such strategies could significantly diminish the persistent shortfall of suitable lungs available for transplantation.

In this issue of the Journal, Michaelsen and colleagues ${ }^{3}$ present a study examining the feasibility and safety of

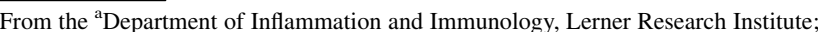
${ }^{\mathrm{b}}$ Department of Thoracic and Cardiovascular Surgery, Heart, Vascular and Thoracic Institute; and ${ }^{\mathrm{c}}$ Transplant Center, Cleveland Clinic, Cleveland, Ohio.

Disclosures: Dr McCurry is a consultant for Lung Bioengineering and Abiomed. All other authors reported no conflicts of interest.

The Journal policy requires editors and reviewers to disclose conflicts of interest and to decline handling or reviewing manuscripts for which they may have a conflict of interest. The editors and reviewers of this article have no conflicts of interest.

Received for publication Dec 15, 2020; revisions received Dec 15, 2020; accepted for publication Dec 16, 2020; available ahead of print Dec 25, 2020.

Address for reprints: Kenneth R. McCurry, MD, 9500 Euclid Ave, Cleveland, OH 44195 (E-mail: mccurrk@ccf.org).

J Thorac Cardiovasc Surg 2022;163:851-2

$0022-5223 / \$ 36.00$

Copyright (C) 2021 Published by Elsevier Inc. on behalf of The American Association for Thoracic Surgery

https://doi.org/10.1016/j.jtcvs.2020.12.074
}

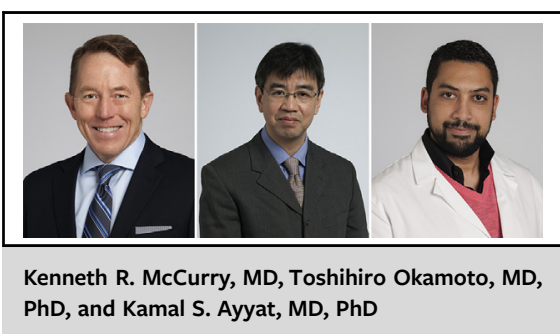

CENTRAL MESSAGE

Administration of continuous high-dose (200 ppm) inhaled nitric oxide during 12-hour porcine ex vivo lung perfusion (EVLP) is safe and may be a novel treatment for lung infection during EVLP.

high-dose inhaled nitric oxide (iNO) as potential antimicrobial treatment during porcine lung EVLP. Lung infection is a common reason for declining donor lungs and can result in poor post-transplant outcomes. ${ }^{4,5}$ Several studies have used high-dose, broad-spectrum antibiotics to treat infected human or pig lungs over 3 to 12 hours of EVLP with good results (reduction in bacterial counts and improved lung function). ${ }^{6-8}$ With such promising studies, why consider the use of iNO?

At high doses, NO has broad-spectrum antimicrobial activity. ${ }^{9}$ Recent clinical studies have used high-dose iNO to successfully treat antibiotic-resistant infections in patients 